Indo. J. Chem. Res, 2018, 6(1), 38-43

\title{
PENGARUH PEMANASAN TERHADAP KRISTALINITAS DAN PARAMETER KISI NANOKOMPOSIT SILIKA-ZIRKONIA MONTMORILLONIT K10 DAN SILIKA-BESI OKSIDA MONTMORILLONIT K10
}

\section{Effect of Heating on The Crystalinity and The Lattice Parameter of Silica-Zirconia Montmorillonite K10 and Silica-Ferri Oxide Montmorillonite K10 Nanocomposites}

\author{
Serly Jolanda Sekewael ${ }^{1 *}$, Karna Wijaya ${ }^{2}$ Triyono $^{2}$ \\ ${ }^{1}$ Department of Chemistry, Faculty of Mathematics and Natural Sciences, Pattimura University \\ Kampus Poka, Jl. Ir. M. Putuhena, Ambon 97134-Indonesia \\ ${ }^{2}$ Chemistry Department, Faculty of Mathematics and Natural Sciences Gadjah Mada University, \\ Bulaksumur, Yogyakarta-Indonesia \\ *Corresponding author: sjsekewael@yahoo.com
}

Received: April 2018 Published: July 2018

\begin{abstract}
The thermal treatment of the silica-zirconia montmorillonite K10 and silica-ferri oxide montmorillonite K10 nanocomposites at 300 and $500{ }^{\circ} \mathrm{C}$ has been carried out, respectively as part of a study of their function as the catalyst. The heating effect on the crystallinity and the lattice parameter calculation of both nanocomposites was studied using XRD and FTIR instruments. The results showed that the nanocomposite silica-zirconia montmorillonite $\mathrm{K} 10$ has a thermal resistance and the crystallinity better than the silica-ferri oxide montmorillonite K10, and both have values varying lattice parameters.
\end{abstract}

Keywords: Crystallinity, nanocomposite, silica-zirconia silica-ferri oxid, montmorillonite K10.

\section{PENDAHULUAN}

Struktur kristal suatu mineral dibangun oleh unit sel, yakni sekumpulan atom yang tersusun secara khusus, yang secara periodik berulang dalam tiga dimensi dalam suatu kisi kristal. Spasi antar unit sel dalam segala arah disebut parameter kisi. Struktur kristal mineral montmorillonit yang merupakan mineral berlapis disusun oleh dua lapisan silikat tetrahedral mengapit satu lapisan silikat oktahedral.

Kestabilan struktur kristal secara kualitatif dapat dipelajari dari stabilitas termal selama dipaparkan dengan peningkatan temperatur. Stabilitas termal adalah salah satu sifat penting pada material padatan berlapis dan berpori agar dapat digunakan sebagai katalis atau adsorben. Padatan montmorilonit terpilar memiliki stabilitas termal yang tinggi, karena pada tahap kalsinasi agen pemilar diubah menjadi bentuk oksidanya yang kaku untuk menyangga struktur antarlapis dengan pori yang permanen (Gill et al.,2010).

Penelitian ini bertujuan untuk mengkaji pengaruh pemanasan terhadap kristalinitas dan parameter kisi montmorillonit dan montmorillonit terpilar campuran oksida logam, yakni montmorillonit K10 serta nanakomposit silika-zirkonia montmorillonit K10 dan silikabesi oksida montmorillonit K10. Nanokomposit montmorillonit K10 terpilar partikel koloid campuran oksida dalam penelitian ini, dibuat menggunakan material montmorillonit sintetik (K10) yang berfungsi sebagai host material. Nama lain montmorillonit K10 adalah bleaching clay, activated clay, dan activated bleaching earth. Memiliki formula kimia: $\mathrm{H}_{2} \mathrm{Al}_{2}\left(\mathrm{SiO}_{3}\right)_{4^{-}}$ $\mathrm{nH}_{2} \mathrm{O}$ (ChemNet ${ }^{\circledR}$ Global Chemical Network, 2013).

Karakterisasi host material dan nanokomposit menggunakan dua instrumen, yakni difraktometer sinar-X (XRD) dan FTIR. XRD digunakan untuk menghitung parameter kisi, ukuran, dan volume kristal setiap sampel, sedangkan FTIR untuk mengetahui pergeseran gugus fungsi dari setiap sampel. 
Serly J. Sekewael dkk. / Indo. J. Chem. Res., 2018, 6(1), 38-43

\section{METODOLOGI}

\section{Bahan}

Montmorillonit K10 (Fluka, Chemica) (selanjutnya disebut Mt-K10), Tetra orto silikat (TEOS), $\mathrm{ZrOCl}_{2} \cdot 8 \mathrm{H}_{2} \mathrm{O}, \quad \mathrm{FeNO}_{3} \cdot 9 \mathrm{H} 2 \mathrm{O}, \mathrm{HCl}$, etanol, $\mathrm{NaOH}$, akuades, akuabides, kertas saring Whatman.

\begin{abstract}
Alat
Seperangkat alat gelas laboratorium, timbangan analitik, $\mathrm{pH}$ meter, desikator, hot plate, stirer, penyaring Buchner, sentrifus, tabung sentrifus, oven gelombang mikro domestik, instrumen: XRD-6000 Shimadzu dan FTIR-Shimadzu PC8201.
\end{abstract}

\section{Prosedur Kerja \\ Preparasi nanokomposit}

Nanokomposit

silika-zirkonia montmorillonit K10 (selanjutnya disingkat SZMK) dan silika-besi oksida montmorillonit K10 (selanjutnya disingkat SFMK), masingmasing dipreparasi dengan mengacu pada penelitian sebelumnya (Sekewael et al., 2016; Sekewael et al., 2017). Langkah pertama adalah pembuatan sol silika. Sol silika dibuat dengan mencampurkan TEOS, $\mathrm{HCl} 2 \mathrm{M}$, dan etanol dengan rasio 41,6 g/10 mL/12 mL. Setelah itu diagingpada temperatur ruang selama 2 jam. Langkah selanjutnya adalah pencampuran sol silika dengan larutan pemilar, baik Zr maupun Fe. Campuran sol yang dibuat kemudian dicampur dengan suspensi Mt-K10 1\% (b/v) yang telah diaging selama 24 jam, dengan perbandingan molar Si/logam pemilar/KTK= $50 / 5 / 1$. Campuran diaduk pada temperatur ruang untuk memfasilitasi pertukaran ion antarlapis montmorillonit dengan partikel-partikel sol campuran oksida. Selanjutnya disentrifugasi. Hasil sentrifugasi dicuci dengan larutan etanol air dengan perbandingan 1:1 selama beberapa kali untuk menghilangkan kelebihan sol silika, setelah itu dikeringkan pada temperatur ruang. Selanjutnya sampel hasil pengeringan diradiasi menggunakan oven gelombang mikro domestik 700 watt selama 10 menit sehinggadiperoleh padatan nanokomposit.

\section{Karakterisasi}

Untuk keperluan analisis, maka sampel MtK10, SZMK, dan SFMK, masing-masing dipanaskan pada temperatur 300 dan $500{ }^{\circ} \mathrm{C}$.

\section{Karakterisasi dengan XRD.}

Sampel Mt-K10 serta nanokomposit SZMK dan SFMK, sebelum dan setelah pemanasan, masing-masing dianalisis dengan metode difraksi sinar-X menggunakan metode bubuk yang diradiasi oleh $\mathrm{CuK} \alpha$ dengan $\lambda=1,5406 \AA$. Dioperasikan pada kondisi: tegangan akselerasi $40 \mathrm{kV}$, arus $30 \mathrm{~mA}$, lebar slit 0,05, dan kecepatan scanning $5 \%$ menit. Pola difraksi sinar-X dari sampel direkam dari $2 \theta$ antara 2-80 derajat, dan keluar sebagai data difraktogram yang selanjutnya dianalisis untuk menentukan perubahan jarak dasar $\mathrm{d}_{001}$.

\section{Karakterisasi dengan FTIR.}

Sampel yang dianalisis digerus dan dihomogenkan dengan $\mathrm{KBr}$ membentuk pelet tipis yang transparan. Pelet ini kemudian diletakkan di dalam sel instrumen spektrofotometer FTIR dan dianalisis. Analisis dilakukan terhadap sampel Mt-K10 serta nanokomposit SZMK dan SFMK untuk menentukan serapan gugus-gugus fungsional.

\section{HASIL DAN PEMBAHASAN}

Langkah awal penelitian ini adalah preparasisol $\mathrm{SiO}_{2}$ sebagai partikel berukuran nanometer. Setelah masing-masing larutan, yakni $\mathrm{ZrOCl}_{2} \cdot 8 \mathrm{H}_{2} \mathrm{O}$ maupun $\mathrm{FeNO}_{3} \cdot 9 \mathrm{H} 2 \mathrm{O}$ ditambahkan kenano-sol $\mathrm{SiO}_{2}$, ion tetramerik bermuatan positif teradsorpsi pada permukaan partikel nano-sol $\mathrm{SiO}_{2}$ bermuatan negatif sedemikian rupa sehingga terbentuk taut silang (Zr-O-Si) atau (Fe-O-Si) disertai dengan disosiasi ikatan (Zr-O-Zr) (Sekewael et al. 2016) atau (Fe-O-Fe) (Sekewael et al, 2017) dalam framework. Hal ini dapat mengakibatkan permukaan partikel nano-sol $\mathrm{SiO}_{2}$ bermuatan positif ketika mengadsorps ion-ion kompleks $\mathrm{Zr}$ atau $\mathrm{Fe}$. Oleh karena itu, nano-sol $\mathrm{SiO}_{2}-\mathrm{ZrO}_{2}$ atau $\mathrm{SiO}_{2}-\mathrm{Fe}_{2} \mathrm{O}_{3}$ bermuatan positif dapat diinterkalasi ke dalam lapisan alumino silikat oleh reaksi pertukaran ion menghasilkan kompleks interkalasi yang diperluas jarak dasarnya. 
Serly J. Sekewael dkk. / Indo. J. Chem. Res., 2018, 6(1), 38-43
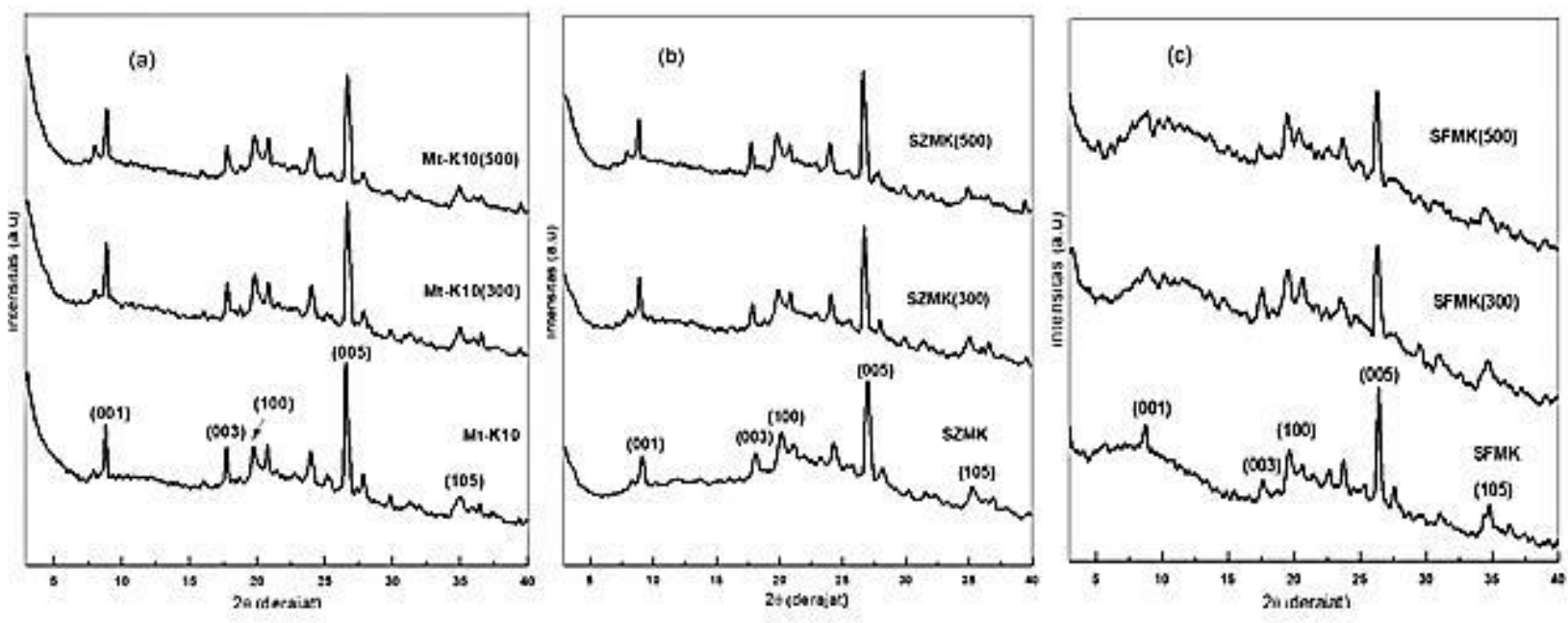

Gambar 1 Difragtogram (a) host Mt-K10 (b) ZMK (c) SFMK pada pemenasan 300 dan $500{ }^{\circ} \mathrm{C}$

Taut silang (Zr-O-Si) atau (Fe-O-Si) lebih lanjut menjadi terhambat akibat pengaruh $\mathrm{pH}$, dan partikel sol akhirnya berubah menjadi oksida pilar berukuran nanometer dalam ruang antarlapis Mt-K10 setelah radiasi dengan gelombang mikro $700 \mathrm{~W}$.

Stabilitas termal host Mt-K10 dan Mt-K10 terpilar dipelajari dari hasil analisis XRD dan FTIR. Difraktogram Mt-K10 serta nanokomposit SZMK dan SFMK ditampilkan pada Gambar 1(a,b,c). Gambar 1.a dan b menunjukkan bahwa pemanasan atau kenaikan temperatur kalsinasi material pada suhu 300 dan $500{ }^{\circ} \mathrm{C}$ nampak tidak berpengaruh terhadap kristalinitas sampel Mt-K10 dan SZMK. Kristalinitas kedua sampel baik Mt-K0 maupun SZMK hampir tidak berubah serta tidak terlihat kerusakan struktur akibat pengaruh panas, yang ditunjukkan oleh retensi intesitas setiap puncak utama dari struktur kedua material, sehingga dapat disimpulkan bahwa kedua sampel stabil secara termal.

Hal yang berbeda dialami nanokomposit SFMK (Gambar 1.c). Pemanasan pada suhu 300 dan $500{ }^{\circ} \mathrm{C}$ menyebabkan runtuhnya bidang dasar (001) silikat montmorillonit dan tidak muncul pada tiga puncak dengan intensitas tertinggi. Terjadi pelebaran pola difraksi dan kristalinitas struktur nanokomposit semakin berkurang, sehingga dapat disimpulkan bahwa nanokomposit SFMK memiliki kestabilan termal yang rendah.

Dari hasil analisis dapat dikatakan bahwa ada pengaruh agen pemilar yang berbeda terhadap stabilitas termal nanokomposit.
Adanya nanokomposit campuran oksida $\mathrm{SiO}_{2^{-}}$ $\mathrm{ZrO}_{2}$ pada antarlapis Mt-K10 memberikan kontribusi terhadap stabilitas termal material tersebut. Hasil penelitian membuktikan bahwa material nanokomposit dengan prekursor pilar logam $\mathrm{Zr}$ lebih stabil secara termal dibandingkan prekursor pilar logam $\mathrm{Fe}$. Hal ini bersesuaian dengan sifat zirkonium oksida yang diketahui diketahui sangat tahan terhadap suhu tinggi. Zirkonium oksida bahkan digunakan untuk pelapis tanur.

Mt-K10 pada Gambar 1(a) memiliki refleksi tajam pada daerah $2 \theta=8,7^{\circ}$ dengan jarak dasar bidang $\mathrm{d}_{001}=10,1 \AA$. Ghebaur et al. (2011) melaporkan refleksi tajam pada daerah $2 \theta=8,9^{\circ}$ dengan bidang $\mathrm{d}_{001}=9,8 \AA$ untuk montmorillonit K10. Terjadinya pilar campuran oksida $\mathrm{SiO}_{2-}$ $\mathrm{ZrO}_{2}$ pada lapisan silikat montmorillonit setelah diradiasi dengan gelombang mikro (SZMK, Gambar 1(b)) ditandai dengan pergeseran bidang (001) ke sudut $2 \theta$ lebih kecil yakni $8,3^{\circ}$ dan peningkatan jarak dasar $\mathrm{d}_{001}$ sebesar $10,65 \AA$. Peningkatan jarak dasar menunjukkan bahwa pada antarlapis silikat montmorillonit terjadi perubahan bentuk agen pemilar dari bentuk terhidrat menjadi bentuk oksida (Sekewael et al, 2016).

Setelah pemanasan pada suhu 300 dan 500 ${ }^{\circ} \mathrm{C}$ host material (Mt-K10) sedikit collaps pada $2 \theta=8,9$ dengan jarak dasar $0,99 \mathrm{~nm}$. Hal ini bersesuaian dengan sifat montmorillonit yang memiliki gaya elektrostatik yang lemah di antara struktur berlapisnya (Singh et al., 2004). Sebaliknya dengan yang disajikan pada Gambar 
Serly J. Sekewael dkk. / Indo. J. Chem. Res., 2018, 6(1), 38-43

1(b), refleksi puncak nanokomposit SZMK tidak mengalami perubahan karena rigiditas struktur yang disumbangkan oleh pilar yang terbentuk dengan bantuan radiasi gelombang mikro.

Tabel 1 Ukuran kristal, Parameter Kisi, dan wolume sel host Mt-K I

\begin{tabular}{|c|c|c|c|c|c|}
\hline \multirow{2}{*}{$\begin{array}{l}\text { Temperatur, } \\
{ }^{\circ} \mathrm{C}\end{array}$} & \multicolumn{5}{|c|}{ MIt-KI0 } \\
\hline & $\mathrm{I}, \mathrm{nm}$ & a, $\mathrm{A}$ & $b, h$ & $c, \lambda$ & $Y, B^{3}$ \\
\hline 0 & 34,11 & 4.56 & 8.97 & 10,19 & 411,05 \\
\hline 300 & 29,76 & 4,54 & 8,99 & 10,13 & 407,75 \\
\hline 500 & 28,00 & 4,54 & 8,95 & 10,13 & 405,93 \\
\hline
\end{tabular}

Tahel 2 Ukaran kristal, Parnmeter Kisi, dan volume nanokomposit SZMK

\begin{tabular}{llllll}
\hline Temperatur, & \multicolumn{5}{c}{ SZAIK } \\
\cline { 2 - 6 }${ }^{\circ} \mathrm{C}$ & $\mathrm{L}, \mathrm{nm}$ & $\mathbf{n , A}$ & $\mathbf{b}, \mathrm{A}$ & $\mathbf{c , A}$ & $\mathrm{Y,A}$ \\
\hline 0 & 21,29 & 4,62 & 8,99 & 10,27 & 420,67 \\
300 & 26,04 & 4,54 & 8,96 & 10,09 & 404,78 \\
500 & 25,69 & 4,53 & 8,98 & 10,16 & 407,60 \\
\hline
\end{tabular}

Tahel 3 Ukuran kristal, Parameter Kisi, dan volume nanokomposit SFMK

\begin{tabular}{|c|c|c|c|c|c|}
\hline \multirow{2}{*}{$\begin{array}{l}\text { Temperatur, } \\
{ }^{\circ} \mathrm{C}\end{array}$} & \multicolumn{5}{|c|}{ SFMIK } \\
\hline & $\mathrm{L}, \mathrm{nm}$ & a, $A$ & $b, d$ & $c, d$ & $\mathrm{Y}, \mathrm{A}^{3}$ \\
\hline 0 & 15,15 & 4,57 & 8,98 & 10,31 & 417,27 \\
\hline 300 & 12.31 & $4,6 !$ & 9,00 & 10,11 & 413,68 \\
\hline 500 & 19,69 & 4,61 & 9,02 & 10,09 & 413,77 \\
\hline
\end{tabular}

Dengan kata lain nanokomposit yang disintesis memiliki daya tahan termal yang baik. Hal ini mencerminkan keteraturan struktur lapisan dua dimensi cukup baik dipertahankan pada suhu ini (Han dan Yamanaka, 2006). Refleksi puncak yang dihasilkan memiliki intensitas lebih rendah, menunjukkkan bahwa campuran oksida yang terbentuk relatif lebih sedikit. Tidak adanya pelebaran puncak menunjukkan formasi dari nanokomposit tertata dengan baik (Riaz dan Ashraf, 2011).

Berdasarkan data hasil analisis XRD dapat dilakukan estimasi parameter kisi kristal (dimensi unit sel) untuk sistim kristal monoklinik milik montmorillonit dengan sudut $\beta=99,54^{\circ}$ (Anthony et al., 2009) terhadap set bidang yang ekivalen, yakni bidang (001) dan (100), dan refleksi pada $2 \theta$ sekitar $60^{\circ}$ untuk bidang $(060)$ (Kawi dan Yao, 1999; Velde dan Meunier, 2008) menggunakan persamaan (1) dan (1) (West, 2010). Sementara estimasi ukuran kristal dari puncak difraksi bidang $\mathrm{d}_{001}$ dihitung menggunakan persamaan Scherrer (persamaan (3) (Monshi et al., 2012).

$$
\begin{gathered}
\frac{1}{\mathrm{~d}^{2}}=\frac{1}{\sin ^{2} \beta}\left(\frac{\mathrm{h}^{2}}{\mathrm{a}^{2}}+\frac{\mathrm{k}^{2} \sin ^{2} \beta}{\mathrm{b}^{2}}+\frac{\mathrm{l}^{2}}{\mathrm{c}^{2}}-\frac{2 \mathrm{hl} \cos \beta}{\mathrm{ac}}\right) \\
\mathrm{V}=\mathrm{abc} \sin \beta \\
\mathrm{L}=\frac{\mathrm{K} \lambda}{\beta \cdot \cos \theta}
\end{gathered}
$$

Keterangan:

$$
\begin{aligned}
& \mathrm{d} \quad=\text { jarak antar bidang kristal } \\
& \mathrm{a}, \mathrm{b}, \mathrm{c}=\text { rusuk bidang (parameter kisi kristal) } \\
& \beta=\text { sudut antara a dan } \mathrm{c} ; \\
& \text { (hkl)=bidang kristal; } \\
& \mathrm{V}=\text { volume kisi kristal. } \\
& \mathrm{L}=\text { ukuran kristal, } \\
& \mathrm{K}=\text { konstanta yang berkaitan dengan bentuk kristal, } \\
& \lambda=\text { panjang gelombang, } \\
& \beta=\text { lebar puncak difraksi pada setengah tinggi } \\
& \quad \quad \text { FWHM) } \\
& \theta=\text { sudut difraksi. }
\end{aligned}
$$

Hasil perhitungan ukuran kristal, parameter kisi, dan volume unit sel host Mt-K10 dan kedua nanokomposit disajikan pada Tabel 1-3. Hasil tabulasi pada Tabel 1-3 menunjukkan dimensi unit sel nanokomposit SZMK dan SFMK lebih besar dibandingkan host Mt-K10. Hal ini disebabkan karena pengaruh masuknya campuran oksida logam dalam struktur host montmorillonit, yang berasosiasi dengan kehadiran ikatan antara partikel oksida logam dengan silikat Mt-K10 pada arah $c$ dalam kisi kristal. Menurut West (2010), kehadiran ikatan logam dari interaksi logam-logam pada arah $c$ dalam kisi kristal dengan unit sel heksagonal pada senyawa dengan struktur NiAs menyebabkan bervariasinya rasio $c / a$, dimensi $c$ nilainya dua kali nilai $a$. Selain itu, adanya campuran oksida baik $\mathrm{SiO}_{2}-\mathrm{ZrO}_{2}$ atau $\mathrm{SiO}_{2}-$ $\mathrm{Fe}_{2} \mathrm{O}_{3}$ di dalam struktur nanokomposit memberikan kontribusi bagi peningkatan volume kisi kristal.

Nilai estimasi parameter kisi $a, b$, dan $c$ untuk host Mt-K10 tidak jauh berbeda dengan nilai parameter kisi montmorillonit hasil analisis dari pola difraksi XRD oleh laporan dalam literatur sebelumnya. van Olphen (1977) memperoleh nilai $a, b$, dan $c$ masing-masing 5,17; 8,9; dan 9,2 , sementara laporan Anthony et al. (2009) masing-masing 5,17; 8,94; dan 9,95 ̊.

Dari hasil estimasi parameter kisi setelah material dipanaskan pada 300 dan $500{ }^{\circ} \mathrm{C}$ (Tabel 1-3), nampak tidak ada pengaruh yang signifikan terhadap nilai $a, b$, dan $c$, sehingga 
dapat dikatakan bahwa kristalinitas material tidak banyak dipengaruhi oleh peningkatan temperatur. Namun bertambahnya temperatur berkontribusi terhadap ukuran kristal dan volume unit sel, terlebih untuk nanokomposit SFMK, yang mana telah dibuktikan oleh difraktogram pada Gambar 1.c, yakni adanya pelebaran puncak difraksi. bergeser ke bilangan gelombang lebih besar yakni $1067 \mathrm{~cm}^{-1}$ (Gambar 2.b). Intensitas serapan tersebut semakin tajam, akibat meningkatnya kuat ikatan $\mathrm{Si}-\mathrm{O}$ dan merupakan indikasi semakin kuatnya ikatan antara lapisan silikat montmorillonit dengan pilar oksida $\mathrm{SiO}_{2-}$ $\mathrm{ZrO}_{2}$. Bertambahnya rasio Si/Al menyebabkan montmorillonit terpilar memiliki daya tahan
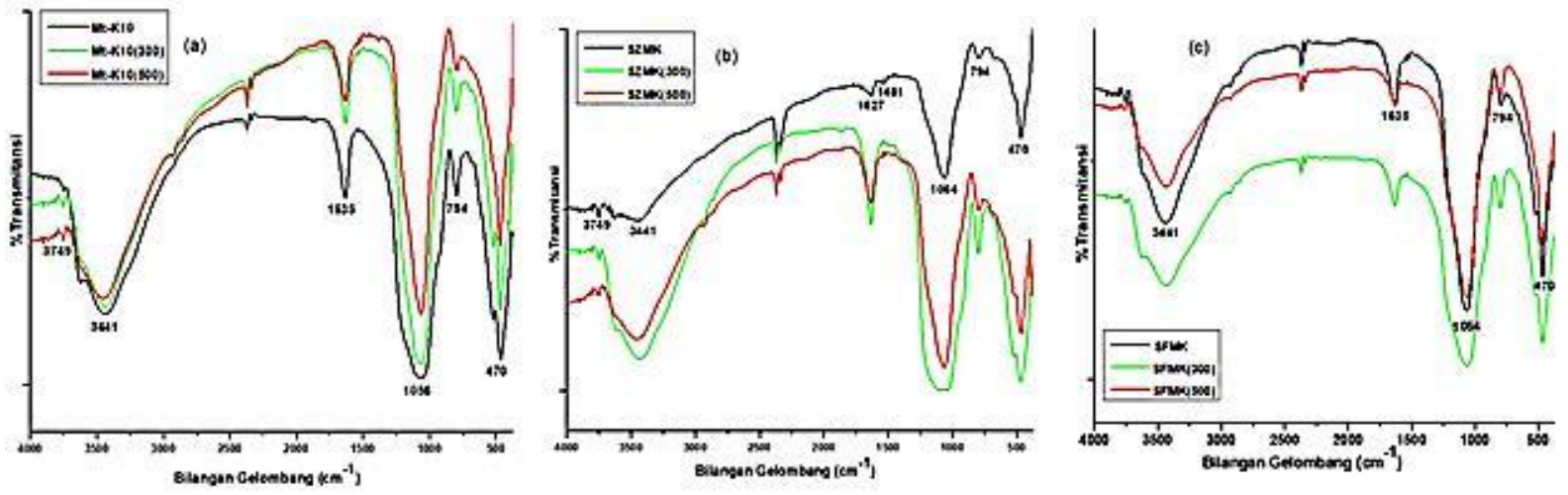

Gambar 2 Spektra FTIR (a) host Mt-K10, (B) SZMK (c) SFMK setelah pemanasan 300

Untuk selanjutnya, hasil analisis berupa spektra IR disajikan pada Gambar 2 (a,b,c). Gambar tersebut memperlihatkan puncak-puncak penting untuk identifikasi montmorillonit. Puncak serapan pada bilangan gelombang 470, 794, 1056, 1635, 3441, dan $3749 \mathrm{~cm}^{-1}$. Pita serapan pada bilangan gelombang 3433dan 3749 $\mathrm{cm}^{-1}$ diidentifikasi sebagai pita vibrasi ulur $-\mathrm{OH}$ molekul air dan vibrasi ulur-OH struktural oktahedral (Al-OH). Pita-pita ini diperkuat dengan pita serapan pada bilangan gelombang $1627 \mathrm{~cm}^{-1}$ yang merupakan pita vibrasi tekuk OH molekul air (Komadel, 2003). Hal ini adalah indikasi bahwa montmorillonit memiliki sifat menyerap air.

Serapan pada $3433 \mathrm{~cm}^{-1}$ merupakan serapan vibrasi ulur gugus $-\mathrm{OH}$ baik itu dari molekul air, silanol, maupun aluminol. Intensitas serapan rentangan $\mathrm{O}-\mathrm{H}$ yang berkurang pada nanokomposit SZMK dan SFMK (Gambar 2(b,c) adalah karena dehidrasi yang dialami selama proses radiasi gelombang mikro berlangsung. Pita serapan pada $470 \mathrm{~cm}^{-1}$ merupakan vibrasi tekuk Si-O-Si. Pita serapan pada $794 \mathrm{~cm}^{-}$ ${ }^{1}$ merupakan karakteristik vibrasi tekuk O-Si-O. Pita serapan pada $1056 \mathrm{~cm}^{-1}$ merupakan serapan khas vibrasi ulur $\mathrm{Si}-\mathrm{O}$ pada lapisan tetrahedral.

Dengan bertambahnya rasio $\mathrm{Si} / \mathrm{Al}$ akibat masuknya oksida $\mathrm{SiO}_{2} / \mathrm{ZrO}_{2}$, maka serapan ini termal yang baik (Yuan et al., 2008). Hal ini didukung oleh data XRD pada Gambar 1.b.

Serapan pada daerah sidik jari yang tetap teramati pada kedua nanokomposit SZMK dan SFMK merupakan indikasi bahwa proses konversi termal dengan radiasi gelombang mikro tidak merusak ikatan $\mathrm{Si}-\mathrm{O}$ atau $\mathrm{Al}-\mathrm{O}$ pada antarlapis silikat montmorillonit. Artinya bahwa struktur dasar lapisan montmorillonit tidak terpengaruh oleh proses pilarisasi (Molu dan Yurdakoç, 2010). Munculnya serapan lemah pada $1481 \mathrm{~cm}^{-1}$ yang teramati pada nanokomposit SZMK merupakan bukti adanya pilar yang memberikan kontribusi kepada keasaman nanokomposit, karena menyumbang situs asam Lewis (Gil et al., 2010).

Pemanasan pada suhu 300 dan $500{ }^{\circ} \mathrm{C}$ tidak mempengaruhi keberadaan serapan gugus-gugus fungsi host Mt-K10 dan nanokomposit Mt-K10 terpilar, dalam arti gugus-gugus fungsi pada serapan bilangan gelombang yang teramati tetap ada. Namun demikian ada sedikit perbedaan dari intensitas serapan dengan pola yang tidak beraturan, terutama untuk nanokomposit hasil sintesis, pada gugus-gugus yang berhubungan dengan vibrasi ulur atau vibrasi tekuk molekul air. Hal yang mirip dilaporkan oleh Reddy et al. (2009). 


\section{KESIMPULAN}

Pemanasan pada suhu 300 dan $500{ }^{\circ} \mathrm{C}$ tidak signifikan mempengaruhi paramater kisi kristal dari material Mt-K10 atau pun nanokomposit SZMK dan SFMK, namun berkontribusi terhadap ukuran kristal dan volume unit sel material tersebut.

\section{UCAPAN TERIMA KASIH}

Ucapan terima kasih penulis sampaikan kepada para teknisi Laboratorium Kimia Analitik dan Kimia Organik Jurusan Kimia FMIPA UGM yang telah berkontribusi dalam penelitian ini.

\section{DAFTAR PUSTAKA}

Anthony, J. W., Bideaux, R. A., Bladh, K. W., Nichols, M. C., 2009, Handbook of mineralogy, Volume 2, University of California.

Gil, A., Korili, S.A., Trujilano, R., Vincente, M.A., 2010, Pillared Clays and Related Catalyst, Springer Science Business Media, New York.

Han, Y.S., Yamanaka, S., 2006, Preparation and characterization of microporous $\mathrm{SiO}_{2}-\mathrm{ZrO}_{2}$ pillared montmorillonite, J. Solid State Chem., 179, 1146-1153.

Kawi, S., Yao, Y.Z., 1999, Silica bonded K10 montmorillonite (SBM): a high surface area catalytic clay material, Microporous Mesoporous Mater, 28, 25-34.

Komadel, P., 2003, Chemically Modified Smectites, Slovac Academy o Sciences, Slovakia, Clay Mineral, 38, 127-138.

Monshi, A., Foroughi, M.R. , Monshi, M.R. , 2012, Modified Scherrer equation to estimate more accurately nano-crystallite size using XRD, World Journal of Nano Science and Engineering, 2, 154-160.
Reddy, C.R., Bhat, Y.S., Nagendrappa, G., Prakash, B.S.J., 2009, Brønsted and Lewis acidity of modified montmorillonite clay catalysts determined by FT-IR spectroscopy, Catal. Today, 141, 157-160.

Riaz, U., Ashraf, S.M., 2011, Effect of solid state intercalation conditions in controlling the self-assembled nanostructured polycarbazole - montmorillonite nanocomposites synthesized by mechanochemical and microwave-assisted techniques, Appl. Clay Sci., 52, 179-183.

Sekewael, S.J., Wijaya, K., Triyono, Budiman, A., 2016, Microwave assisted preparation and physico-chemical properties of mixed oxides silica-zirconia montmorillonite K10 nanocomposite, Asian J. Chem., 28(10), 2325-2330.

Sekewael, S.J., Wijaya, K., Triyono, Budiman, A., 2017,Nanocomposite of modified montmorillonite $\mathrm{K} 10$ with $\mathrm{SiO}_{2}-\mathrm{Fe}_{2} \mathrm{O}_{3}$ as a catalyst of biodiesel synthesis, Int.J.ChemTech.Res., 10(1), 62-70.

van Olphen, H., 1977, Clay colloid chemistry, second edition, A Willey-Interscience Publication.

Velde, B.,and Meunier, A., 2008, The Origin of Clay Minerals in Soils and Weathered Rocks, Berlin, Heidelberg, New York: Springer-Verlag, pp 4-6, ISBN 9783540 756330.

West, A. R., 2010, Basic Solid Chemistry, John Wiley \& Sons Ltd, England.

Yuan, P., Bergaya,F.A., Tao, Q., Fan,M., Liu,Z., Zhu,J., He,H., Tianhu Chen, 2008, A combined study by XRD, FTIR, TG and HRTEM on the structure of delaminated Feintercalated/pillared clay, J. Colloid Interface Sci., 324,142-149. 